\title{
T-S Fuzzy Tracking Control of Surface-Mounted Permanent Magnet Synchronous Motors with a Rotor Acceleration Observer
}

\author{
Jin-Woo Jung ${ }^{*}$, Han Ho Choi ${ }^{*}$, and Tae-Heoung $\mathrm{Kim}^{\dagger}$ \\ *Division of Electronics and Electrical Engineering, Dongguk University, Seoul, Korea \\ ${ }^{\dagger}$ Dept. of Electrical Engineering, Engineering Research Institute, Gyeongsang National University, Jinju, Korea
}

\begin{abstract}
This paper proposes a fuzzy speed tracking controller and a fuzzy rotor angular acceleration observer for a surface-mounted permanent magnet synchronous motor (SPMSM) based on the Takagi-Sugeno (T-S) fuzzy model. The proposed observer-based controller is robust to load torque variations since it utilizes rotor angular acceleration information instead of the load torque value. Linear matrix inequality (LMI) sufficient conditions are given to compute the gain matrices of the speed tracking controller and the observer. In addition, it is mathematically verified that the proposed observer-based control system is asymptotically stable. Simulation and experimental results are presented to confirm that the proposed control algorithm assures a better transient behavior and less sensitivity under model parameter variations than the conventional PI control method.
\end{abstract}

Key words: Acceleration observer, Fuzzy control, Robust control, Surface-mounted permanent magnet synchronous motor (SPMSM)

\section{INTRODUCTION}

With the rapid growth of high-speed switching devices and digital signal processors (DSP), permanent magnet synchronous motors (PMSM) are increasingly employed in numerous industrial applications due to their many benefits such as fast dynamics, high efficiency, low inertia, high power density, robustness, etc [1]-[14]. However, it is not easy to achieve a fast transient response and robust performance with a PMSM due to their nonlinearities, unmodeled disturbances and motor parameter variations. Hence, it is generally well-known that linear control strategies such as PI control and LQ regulators cannot guarantee a sufficiently high performance throughout the entire operating range. Accordingly, nonlinear control schemes, e.g., the adaptive control method [4]-[6], the nonlinear feedback linearization control method [7]-[8], and

Manuscript received Jul. 30, 2010; revised Jan. 26, 2012

Recommended for publication by Associate Editor Jang-Mok Kim

${ }^{\dagger}$ Corresponding Author: ktheoung@gnu.ac.kr

Tel: +82-55-772-1717, Gyeongsang Nat'l University

*Division of Electronics and Electrical Engineering, Dongguk University, Korea the sliding-mode control method [9]-[11], have become an alternative solution to accurately control the position or speed of a PMSM. Lately, some papers have reported fuzzy control schemes [12]-[14] which take into consideration the nonlinearities or uncertainties of a PMSM. Even though some of the previous PMSM fuzzy control methods show good results, most of them use the heuristics-based fuzzy model. In addition, almost all of the previous methods lack systematic stability analysis and controller design.

Based on the Takagi-Sugeno (T-S) fuzzy model, a fuzzy tracking controller and a fuzzy rotor angular acceleration observer have been proposed that can precisely track the desired trajectory of a PMSM. Unlike previous fuzzy methods [12]-[14], the control design method and stability analysis are systematically introduced. First, the LMI existence conditions are derived to obtain the gains for the fuzzy tracking controller and the fuzzy acceleration observer. It is then analytically proven that the observer-based fuzzy tracking control system is exponentially stable. To demonstrate the effectiveness of the proposed control algorithm, simulation and experimental results are presented under model parameter variations.

This paper is organized as follows. Section II describes the 
SPMSM model. In Section III, the design of a fuzzy controller and a fuzzy angular acceleration observer is addressed in detail. The stability of the observer-based fuzzy control system is analyzed in Section IV. Section V presents the simulation and experimental results. Finally, conclusions are given in Section VI.

\section{SPMSM MODEL}

The mechanical and electrical equations of a surface-mounted PMSM (SPMSM) in the rotor reference frame can be represented by:

$$
\begin{aligned}
& \dot{\theta}=\omega \\
& \dot{\omega}=k_{1} i_{q s}-k_{2} \omega-k_{3} T_{L} \\
& \dot{i}_{q s}=-k_{4} i_{q s}-k_{5} \omega+k_{6} V_{q s}-\omega i_{d s} \\
& \dot{i}_{d s}=-k_{4} i_{d s}+k_{6} V_{d s}+\omega i_{q s}
\end{aligned}
$$

where, $T_{L}$ denotes the load torque, $\theta$ is the electrical rotor angular position, $\omega$ is the electrical rotor angular speed, $i_{q s}$ is the $q$-axis current, $V_{q s}$ is the $q$-axis voltage, $i_{d s}$ is the $d$-axis current, $V_{d s}$ is the $d$-axis voltage, $p$ is the number of poles, $R_{s}$ is the stator resistance, $L_{s}$ is the stator inductance, $J$ is the rotor inertia, $B$ is the viscous friction coefficient, $\lambda_{m}$ is the magnetic flux, and $k_{i}>0, i=1-6$ are the parameter values given by:

$$
\begin{aligned}
& k_{1}=\frac{3}{2} \frac{1}{J} \frac{p^{2}}{4} \lambda_{m}, k_{2}=\frac{B}{J}, k_{3}=\frac{p}{2 J}, \\
& k_{4}=\frac{R_{s}}{L_{s}}, k_{5}=\frac{\lambda_{m}}{L_{s}}, k_{6}=\frac{1}{L_{s}}
\end{aligned}
$$

In this paper, the following assumptions are used to design a fuzzy tracking controller and a fuzzy angular acceleration observer:

A1: $\theta, i_{q s}, i_{d s}$ are available.

A2: $T_{L}$ is unknown and $\dot{T}_{L}$ can be set as 0 .

A3: The desired trajectories $\theta_{d}, \dot{\theta}_{d}=\omega_{d}, \dot{\omega}_{d}, \ddot{\omega}_{d}$ are bounded.

(1) will be transformed to a model with the rotor angular acceleration as a state variable. The electrical angular acceleration is defined as $\beta=\dot{\omega}$. Then the following model can be obtained from (1) and A2:

$$
\begin{aligned}
& \dot{\theta}=\omega \\
& \dot{\omega}=\beta \\
& \dot{\beta}=-k_{2} \beta-k_{1} k_{4} i_{q s}-k_{1} k_{5} \omega-k_{1} \omega i_{d s}+k_{1} k_{6} V_{q s} \\
& \dot{i}_{d s}=-k_{4} i_{d s}+\omega i_{q s}+k_{6} V_{d s}
\end{aligned}
$$

The above model (2) does not need the load torque value but it does need the angular acceleration information. Unfortunately, accurate knowledge of rotor acceleration is usually not available in industrial applications since an accelerometer is expensive and the differentiated speed is sensitive to noise. Therefore, this study focuses on designing a state feedback control law and an acceleration observer for the system model (2).

\section{DESIGN OF THE FUZZY TRACKING CONTROLLER AND THE FUZZY ACCELERATION OBSERVER}

\section{A. Fuzzy Tracking Controller Design}

The concept behind T-S fuzzy modeling is summarized as follows. First, a nonlinear system is divided into $r$ simple local linear subsystem models with $r$ operating points, and then the local linear model for each of the operating points is obtained by using a linearization technique [15]-[17].

The control inputs $\left(V_{q s}, V_{d s}\right)$ are defined as:

$$
\begin{aligned}
& V_{q s}=\frac{1}{k_{1} k_{6}}\left(u_{q}+u_{q f b}\right), V_{d s}=\frac{1}{k_{6}}\left(u_{d}+u_{d f b}\right) \\
& u_{q}=k_{1} k_{4} i_{q s}+k_{1} k_{5} \omega_{d}-\ddot{\omega}_{d}-k_{2} \dot{\omega}_{d}, u_{d}=-i_{q s} \omega
\end{aligned}
$$

where, $u_{q}$ and $u_{d}$ are the linearizing control terms to compensate for the nonlinearities of a PMSM, and $u_{q f b}$ and $u_{d f b}$ are the feedback control terms to stabilize the error dynamics.

Next, let the position error $\left(\theta_{e}\right)$, speed error $\left(\omega_{e}\right)$ and acceleration error $\left(\beta_{e}\right)$ be defined as:

$$
\theta_{e}=\theta-\theta_{d}, \omega_{e}=\omega-\omega_{d}, \beta_{e}=\dot{\omega}_{e}=k_{1} i_{q s}-k_{2} \omega-k_{3} T_{L}-\dot{\omega}_{d}
$$

By introducing a T-S fuzzy model, the PMSM model (2) can be approximated by a third-order $r$-rule fuzzy model. In this paper, the motor speed $\omega$ is selected to be a scheduling variable. From (2) to (4), the $i$ th rule of a T-S fuzzy model is represented by the following:

System Rule $i$ : IF $\omega$ is $F_{i}$, THEN

$$
\begin{aligned}
& \dot{\theta}_{e}=\omega_{e} \\
& \dot{\omega}_{e}=\beta_{e} \\
& \dot{\beta}_{e}=-k_{1} k_{5} \omega_{e}-k_{2} \beta_{e}-k_{1} W_{i} i_{d s}+u_{q f b} \\
& \dot{i}_{d s}=-k_{4} i_{d s}+u_{d f b}
\end{aligned}
$$

where, $F_{i}(i=1-r)$ denote the fuzzy sets that are characterized by the membership function $m_{i}(\omega), r$ is the number of fuzzy rules, and $W_{i}$ is the $i$ th operating point. By using a standard fuzzy inference rule, the following global nonlinear model can be derived: 


$$
\begin{aligned}
& \dot{\theta}_{e}=\omega_{e} \\
& \dot{\omega}_{e}=\beta_{e} \\
& \dot{\beta}_{e}=-k_{1} k_{5} \omega_{e}-k_{2} \beta_{e}-k_{1} \sum_{i=1}^{r} h_{i}(\omega) W_{i} i_{d s}+u_{q f b} \\
& \dot{i}_{d s}=-k_{4} i_{d s}+u_{d f b}
\end{aligned}
$$

where, $h_{i}(\omega)=m_{i}(\omega) / \sum_{j=1}^{r} m_{j}(\omega), m_{i}: R \rightarrow[0,1], i=1, \cdots r$ is the membership function of the system with respect to the plant rule $i, h_{i}(\omega)$ which denotes the normalized weight of each IF-THEN rule, and it satisfies $h_{i}(\omega) \geq 0$ and $\sum_{i=1}^{r} h_{i}(\omega)=1$.

The global fuzzy model (6) can be rewritten in a state-space form as:

$$
\dot{x}=\sum_{i=1}^{r} h_{i}(\omega) A_{i} x+B u
$$

where,

$$
\begin{aligned}
& A_{i}=\left[\begin{array}{cccc}
0 & 1 & 0 & 0 \\
0 & 0 & 1 & 0 \\
0 & -k_{1} k_{5} & -k_{2} & -k_{1} W_{i} \\
0 & 0 & 0 & -k_{4}
\end{array}\right], B=\left[\begin{array}{ll}
0 & 0 \\
0 & 0 \\
1 & 0 \\
0 & 1
\end{array}\right], x=\left[\begin{array}{c}
\theta_{e} \\
\omega_{e} \\
\beta_{e} \\
i_{d s}
\end{array}\right], \\
& u=\left[\begin{array}{ll}
u_{q f b} & u_{d f b}
\end{array}\right]^{T} .
\end{aligned}
$$

Assume that the local tracking controller is represented by the following controller.

\section{Controller Rule $i$ : IF $\omega$ is $F_{i}$, THEN}

$$
\begin{aligned}
& u_{q}=k_{1} k_{4} i_{q s}+k_{1} k_{5} \omega_{d}-\ddot{\omega}_{d}-k_{2} \dot{\omega}_{d}, u_{d}=-i_{q s} \omega \\
& u=\left[u_{q f b}, u_{d f b}\right]^{T}=K_{i} x
\end{aligned}
$$

where, $K_{i} \in R^{2 \times 4}$ denotes the controller gain matrices. Then, the final fuzzy tracking regulator can be expressed by the weighted average of each local controller as follows:

$$
\begin{aligned}
& V_{q s}=\frac{1}{k_{1} k_{6}}\left(u_{q}+u_{q f b}\right), V_{d s}=\frac{1}{k_{6}}\left(u_{d}+u_{d f b}\right), \\
& u_{q}=k_{1} k_{4} i_{q s}+k_{1} k_{5} \omega_{d}-\ddot{\omega}_{d}-k_{2} \dot{\omega}_{d}, u_{d}=-i_{q s} \omega \\
& u=\left[u_{q f b}, u_{d f b}\right]^{T}=\sum_{i=1}^{r} h_{i}(\omega) K_{i} x
\end{aligned}
$$

Fig. 1 shows a block diagram of the proposed fuzzy tracking controller and the closed-loop control system is given in the

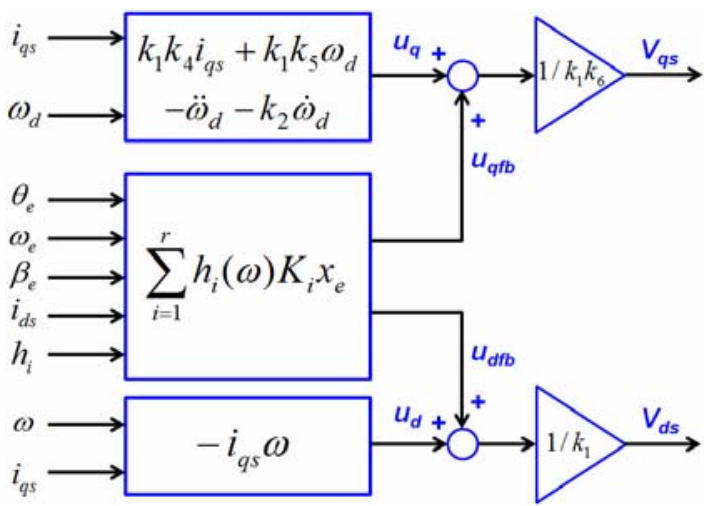

Fig. 1. Block diagram of the proposed fuzzy tracking controller.

following equation:

$$
\dot{x}=\sum_{i=1}^{r} h_{i}(\omega)\left(A_{i}+B K_{i}\right) x
$$

Next, to obtain the gain of the fuzzy tracking regulator, assume that the following LMI condition is feasible:

$$
\begin{aligned}
X>0,\left(A_{i}+\right. & \alpha I) X+X\left(A_{i}+\alpha I\right)^{T} \\
& +B Y_{i}+Y_{i}^{T} B^{T}<0, \quad \forall i
\end{aligned}
$$

where, $X \in R^{4 \times 4}$ and $Y_{i} \in R^{2 \times 4}$ are decision variables and $\alpha \geq$ 0 is the minimum decay rate. Also, assume that the gain matrices $K_{i}$ are calculated by the following equation:

$$
K_{i}=Y_{i} X^{-1}
$$

If there is a solution $\left(X, Y_{i}\right)$ to satisfy (11), there also exists a matrix $Q_{c}>0$ such that:

$$
P_{c} A_{i}+A_{i}^{T} P_{c}+P_{c} B K_{i}+K_{i}^{T} B^{T} P_{c} \leq-Q_{c}<0, \forall i
$$

where, $P_{c}=X^{l}$. If the Lyapunov function is defined as $V_{c}(x)=$ $x^{T} P_{c} x$, its derivative with respect to time is given by:

$$
\begin{aligned}
\dot{V}_{c}(x) & =\frac{d}{d t} x^{T} P_{c} x=2 x^{T} \sum_{i=1}^{r} h_{i}(\omega) P_{c}\left[A_{i}+B K_{i}\right] x \\
& \leq-2 \alpha x^{T} P_{c} x \leq 0
\end{aligned}
$$

Therefore, the fuzzy controller is exponentially stable because the state error converges to zero with a minimum decay rate $\alpha$. This means that the LMI condition (11) is feasible for $\left(X, Y_{i}\right)$, the gain matrices $K_{i}$ are given by (12) [18]. Then, $x$ converges exponentially to zero.

\section{B. Fuzzy Acceleration Observer Design}

The proposed fuzzy control system is very insensitive to load torque variations because the system model (2) does not 
require the load torque value $T_{L}$. However, the fuzzy controller shown in (9) requires the rotor angular acceleration $\beta$ which is very difficult to obtain in real industrial applications. In this section, a fuzzy acceleration observer which can accurately estimate $\beta$ will be described. Assume that the local acceleration observer is represented by the following linear observer:

\section{Observer Rule $i$ : IF $\omega$ is $F_{i}$, THEN}

$$
\dot{x}_{o}=A_{o i} x_{o}-L_{i}\left(y-C x_{o}\right)+B_{o} u, \hat{\beta}_{e}=C_{o} x_{o}
$$

where, $L_{i} \in R^{3 \times 2}$ are the observer gain matrices, $\hat{\beta}_{e}$ is an estimate of $\beta_{e}, y=C x_{c}$, and:

$$
x_{o}=\left[\begin{array}{lll}
\hat{\omega}_{e} & \hat{\beta}_{e} & \hat{i}_{d s}
\end{array}\right]^{T}, C=\left[\begin{array}{lll}
1 & 0 & 0 \\
0 & 0 & 1
\end{array}\right], C_{o}=\left[\begin{array}{lll}
0 & 1 & 0
\end{array}\right],
$$$$
A_{o i}=\left[\begin{array}{ccc}
0 & 1 & 0 \\
-k_{1} k_{5} & -k_{2} & -k_{1} W_{i} \\
0 & 0 & -k_{4}
\end{array}\right], \quad B_{o}=\left[\begin{array}{ll}
0 & 0 \\
1 & 0 \\
0 & 1
\end{array}\right], \quad x_{c}=\left[\begin{array}{c}
\omega_{e} \\
\beta_{e} \\
i_{d s}
\end{array}\right] \text {. }
$$

Thus the final fuzzy observer can be written as the weighted average of each of the local observers below and Fig. 2 depicts a block diagram of the proposed fuzzy acceleration observer.

$$
\dot{x}_{o}=\sum_{i=1}^{r} h_{i}(\omega)\left[A_{o i} x_{o}-L_{i}\left(y-C x_{o}\right)\right]+B_{o} u, \hat{\beta}_{e}=C_{o} x_{o}
$$

By using the fuzzy plant model (7) and the fuzzy observer model (16), the following error dynamics can be obtained:

$$
\dot{z}=\sum_{i=1}^{r} h_{i}(\omega)\left[A_{o i}+L_{i} C\right] z
$$

where, $z=x_{c}-x_{o}$.

Next, to obtain the gain of the fuzzy acceleration observer, assume that the following LMI condition is feasible:

$$
\begin{aligned}
P_{o}>0, P_{o}\left(A_{o i}+\alpha I\right) & +\left(A_{o i}+\alpha I\right)^{T} P_{o} \\
& +Z_{i} C+C^{T} Z_{i}^{T}<0, \forall i
\end{aligned}
$$

where, $P_{o} \in R^{3 \times 3}$ and $Z_{i} \in R^{3 \times 2}$ are the decision variables and $\alpha \geq 0$ is the minimum decay rate. Also assume that the observer gain matrices $L_{i}$ are given by the following equation:

$$
L_{i}=P_{o}^{-1} Z_{i}
$$

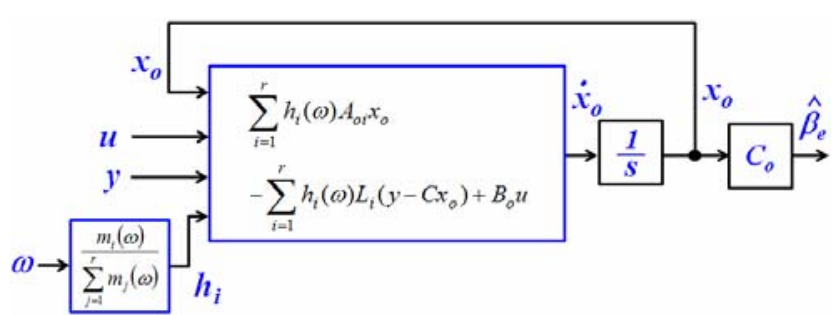

Fig. 2. Block diagram of the proposed fuzzy acceleration observer.

a matrix $Q_{o}>0$ such that:

$$
P_{o} A_{o i}+A_{o i}{ }^{T} P_{o}+Z_{i} C+C^{T} Z_{i}^{T} \leq-Q_{o}<0, \forall i
$$

If the Lyapunov function is defined as $V_{o}(z)=z^{T} P_{o} z$, its time derivative along the error dynamics (17) is given by:

$$
\begin{aligned}
& \dot{V}_{o}(z)=\frac{d}{d t} z^{T} P_{o} z=2 z^{T} \sum_{i=1}^{r} h_{i}(\omega) P_{o}\left[A_{o i}+L_{i}\right] z \\
& \quad=2 z^{T} \sum_{i=1}^{r} h_{i}(\omega)\left[P_{o} A_{o i}+Z_{i} C\right] z \leq-2 \alpha z^{T} P_{o} z \leq 0
\end{aligned}
$$

Consequently, the fuzzy observer is asymptotically stable because the estimation error exponentially converges to zero with a minimum decay rate $\alpha$. This means that the LMI condition (18) is feasible for $\left(P_{o}, Z_{i}\right)$, and the gain matrices $L_{i}$ are calculated by (19) [18]. Then, $z$ converges exponentially to zero.

\section{STABILITY ANALYSIS OF THE OBSERVER-BASED FUZZY CONTROL SYSTEM}

In this section, the stability of the augmented control system, including the fuzzy tracking controller and the fuzzy angular acceleration observer, is analyzed. Assume that the observer-based control system is exponentially stable. Furthermore, if the fuzzy controller and the fuzzy observer can be independently designed, the following theorem is obtained.

Theorem 1: Assume that the LMI conditions (11) and (18) are feasible, and that the following observer-based control law is used instead of (9):

$$
\begin{aligned}
& V_{q s}=\frac{1}{k_{1} k_{6}}\left(u_{q}+u_{q f b}\right), V_{d s}=\frac{1}{k_{6}}\left(u_{d}+u_{d f b}\right), \\
& u_{q}=k_{1} k_{4} i_{q s}+k_{1} k_{5} \omega_{d}-\ddot{\omega}_{d}-k_{2} \dot{\omega}_{d}, u_{d}=-i_{q s} \omega \\
& u=\left[u_{q f b}, u_{d f b}\right]^{T}=\sum_{i=1}^{r} h_{i}(\omega) K_{i} x_{e}
\end{aligned}
$$


where, $\quad x_{e}=\left[\begin{array}{llll}\theta_{e} & \omega_{e} & \hat{\beta}_{e} & i_{d s}\end{array}\right]^{T}$ and $\hat{\beta}_{e}$ is the rotor acceleration error estimated by the fuzzy observer (16). Thus $x$ and $z$ exponentially converge to zero.

Proof: It should be noted that $x_{e}$ can be rewritten as $x_{e}=x-$ Ez because $\beta_{e}-\hat{\beta}_{e}=[0,1,0] z$.

where, $E=\left[\begin{array}{lll}0 & 0 & 0 \\ 0 & 0 & 0 \\ 0 & 1 & 0 \\ 0 & 0 & 0\end{array}\right]$.

Define the Lyapunov function as $V(x, z)=x^{T} P_{c} x+\xi^{T} P_{o} z$ where, $\zeta$ is a sufficiently large scalar, and $P_{c}$ and $P_{o}$ satisfy the LMIs (11) and (18). Its time derivative is expressed as:

$$
\begin{aligned}
\dot{V}(x, z)= & 2 x^{T} P_{c} \dot{x}+2 \xi^{T} P_{o} \dot{z}=2 x^{T} \sum_{i=1}^{r} h_{i}(\omega) P_{c} A_{i} x \\
& +2 x^{T} \sum_{i=1}^{r} h_{i}(\omega) P_{c} B K_{i} x_{e}+2 \xi z^{T} \sum_{i=1}^{r} h_{i}(\omega) P_{o}\left[A_{c i}+L_{i} C\right] z \\
\leq & 2 x^{T} \sum_{i=1}^{r} h_{i}(\omega) P_{c}\left(A_{i}+B K_{i}\right) x \\
& -2 x^{T} \sum_{i=1}^{r} h_{i}(\omega) P_{c} B K_{i} E z-\xi \lambda_{\min }\left(Q_{o}\right)\|z\|^{2} \\
\leq & -\lambda_{\min }\left(Q_{c}\right)\|x\|^{2}-\xi \lambda_{\min }\left(Q_{o}\right)\|z\|^{2}+2 \sigma\|x\| \cdot\|z\|
\end{aligned}
$$

where, $\sigma=\sum_{i=1}^{r}\left\|P_{c} B K_{i} E\right\|$. If $\sigma$ is large enough to guarantee $\xi>\sigma^{2} \lambda_{\min }^{-1}\left(Q_{c}\right) \lambda_{\min }^{-1}\left(Q_{o}\right)$, then $\dot{V}<0$ for all $(x, z) \neq 0$. This means that $(x, z)$ exponentially converge to zero.

Remark 1: It should be noted that the LMIs (11) and (18) are always feasible and thus the problem of designing $K_{i}$ and $L_{i}$ is always feasible. If $L_{i}$ is set as:

$$
L_{i}=\left[\begin{array}{cc}
0 & 0 \\
0 & k_{1} W_{i} \\
0 & 0
\end{array}\right]
$$

then $A_{o i}+L_{i} C$ is reduced to:

$$
A_{o i}+L_{i} C=A_{c l}=\left[\begin{array}{ccc}
0 & 1 & 0 \\
-k_{1} k_{5} & -k_{2} & 0 \\
0 & 0 & -k_{4}
\end{array}\right]
$$

which leads to the third-order stable characteristic function $\left(s+k_{4}\right)\left(s^{2}+k_{2} s+k_{1} k_{5}\right)$. This implies the existence of a Lyapunov matrix $P_{0}$ for some small $\alpha>0$ :

$$
\begin{aligned}
& P_{o}\left(A_{c l}+\alpha I\right)+\left(A_{c l}+\alpha I\right)^{T} P_{o}= \\
& \quad P_{o}\left(A_{o i}+L_{i} C+\alpha I\right)+\left(A_{o i}+L_{i} C+\alpha I\right)^{T} P_{o}<0
\end{aligned}
$$

TABLE I

\section{SPMSM PARAMETERS}

\begin{tabular}{|c|c|}
\hline Number of poles $(p)$ & 12 \\
\hline Rated power $\left(P_{\text {rated }}\right)$ & $750[\mathrm{~W}]$ \\
\hline Rated phase current $\left(I_{\text {rated }}\right)$ & $3.94[\mathrm{~A}]$ \\
\hline Rated torque $\left(T_{\text {rated }}\right)$ & $3.87[N \cdot \mathrm{m}]$ \\
\hline Stator resistance $\left(R_{s}\right)$ & $0.99[\Omega]$ \\
\hline Stator inductance $\left(L_{s}\right)$ & $5.82[\mathrm{mH}]$ \\
\hline Magnetic flux $\left(\lambda_{m}\right)$ & $7.92 \times 10^{-2}[\mathrm{~V} \cdot \mathrm{sec} / \mathrm{rad}]$ \\
\hline Equivalent inertia $(J)$ & $1.21 \times 10^{-3}\left[\mathrm{~kg} \cdot \mathrm{m}^{2}\right]$ \\
\hline Viscous friction coefficient $(B)$ & $0.3 \times 10^{-3}[\mathrm{~N} \cdot \mathrm{m} \cdot \mathrm{sec} / \mathrm{rad}]$ \\
\hline Load torque $\left(T_{L}\right)$ & $1[\mathrm{~N} \cdot \mathrm{m}]$ \\
\hline
\end{tabular}

which guarantees that the LMI (18) is always feasible and a solution is given by $P=P_{0}, Z_{i}=P_{0} L_{i}$. Similarly, it can be easily shown that the LMI (11) is always feasible.

\section{VERIFICATIONS}

To evaluate the performance of the proposed control scheme, simulation and experimental results are presented. Table I shows the nominal parameter values for a prototype PMSM. From the parameters the following dynamic equations can be obtained:

$$
\begin{aligned}
& \dot{\theta}=\omega \\
& \dot{\omega}=\beta \\
& \dot{\beta}=-0.2484 \beta-602090 i_{q s}-48140 \omega \\
& \quad \quad-3539.6 \omega i_{d s}+608100 V_{q s} \\
& \dot{i}_{d s}=-170.1 i_{d s}+\omega i_{q s}+171.8 V_{d s}
\end{aligned}
$$

In this paper, a fuzzy controller and a fuzzy angular acceleration observer that guarantee the minimum decay rate $\alpha=500$ will be designed. The PMSM model (27) is approximated by using the following two-rule fuzzy model:

System Rule 1: IF $\omega$ is about $W_{l}$, THEN $\dot{x}=A_{1} x+B u$

System Rule 2: IF $\omega$ is about $W_{2}$, THEN $\dot{x}=A_{2} x+B u$

where,

$$
\begin{aligned}
A_{1} & =\left[\begin{array}{cccc}
0 & 1 & 0 & 0 \\
0 & 0 & 1 & 0 \\
0 & -48140 & -0.2484 & -3539.6 W_{1} \\
0 & 0 & 0 & -170.1
\end{array}\right], \\
A_{2} & =\left[\begin{array}{cccc}
0 & 1 & 0 & 0 \\
0 & 0 & 1 & 0 \\
0 & -48140 & -0.2484 & -3539.6 W_{2} \\
0 & 0 & 0 & -170.1
\end{array}\right],
\end{aligned}
$$


$B=\left[\begin{array}{ll}0 & 0 \\ 0 & 0 \\ 1 & 0 \\ 0 & 1\end{array}\right]$

In this paper, the following normalized membership functions are chosen based on knowledge and experience.

$$
\begin{aligned}
& h_{1}(\omega)=\frac{m_{1}(\omega)}{m_{1}(\omega)+m_{2}(\omega)}=\frac{e^{-\mu\left(\omega-W_{1}\right)^{2}}}{e^{-\mu\left(\omega-W_{1}\right)^{2}}+e^{-\mu\left(\omega-W_{2}\right)^{2}}}, \\
& h_{2}(\omega)=1-h_{1}(\omega)
\end{aligned}
$$

where, $W_{1}=-W_{2}=W_{R}=1000$ and $\mu=1 / W_{R}^{2}$. Fig. 3 shows the normalized membership functions used in this paper. By solving the LMI condition (18), the following solution $\left(P_{o}\right.$, $Z_{i}$ ) can be obtained.

$$
\begin{aligned}
P_{o} & =\left[\begin{array}{ccc}
73.4865 & -0.1608 & 0.0000 \\
-0.1608 & 0.0002 & 0.0000 \\
0.0000 & 0.0000 & 0.1362
\end{array}\right], \\
Z_{1} & =10^{5} \times\left[\begin{array}{cr}
-0.2980 & -3.5804 \\
0.0004 & 0.0103 \\
0.0000 & -0.0004
\end{array}\right], Z_{2}=10^{5} \times\left[\begin{array}{cc}
-0.2980 & -3.5804 \\
0.0004 & -0.0103 \\
0.0000 & -0.0004
\end{array}\right]
\end{aligned}
$$

As a result, the acceleration observer gains can be calculated by (19).

$$
L_{1}=10^{4} \times\left[\begin{array}{cc}
-0.12 & 0.39 \\
-36.56 & 399.27 \\
0.0000 & -0.03
\end{array}\right], L_{2}=10^{4} \times\left[\begin{array}{cc}
-0.12 & -0.39 \\
-36.56 & -399.27 \\
0.0000 & -0.03
\end{array}\right]
$$

By solving the LMI condition (11), the following solution $\left(X, Y_{i}\right)$ can be obtained:

$$
\begin{array}{r}
X=10^{8} \times\left[\begin{array}{cccc}
0.0000 & 0.0000 & 0.0000 & 0.0000 \\
0.0000 & 0.0000 & -0.0063 & 0.0000 \\
0.0000 & -0.0063 & 4.4005 & 0.0000 \\
0.0000 & 0.0000 & 0.0000 & 0.0000
\end{array}\right], \\
Y_{1}=10^{11} \times\left[\begin{array}{cccc}
0.0000 & 0.0024 & -2.5029 & 0.0000 \\
0.0000 & 0.0000 & 0.0000 & 0.0000
\end{array}\right], \\
Y_{2}=10^{11} \times\left[\begin{array}{llll}
0.0000 & 0.0024 & -2.5029 & 0.0000 \\
0.0000 & 0.0000 & 0.0000 & 0.0000
\end{array}\right]
\end{array}
$$
(12)

$K_{1}=\left[\begin{array}{cccc}-100.0 & -999750.0 & -2000.0 & 0.0000 \\ 0.0000 & 0.0000 & 0.0000 & -10.0\end{array}\right]$,

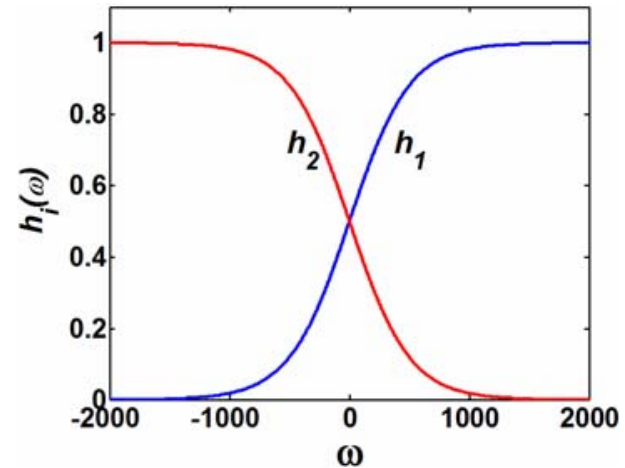

Fig. 3. Normalized membership functions $\left(h_{1}(\omega)\right.$ and $\left.h_{2}(\omega)\right)$.

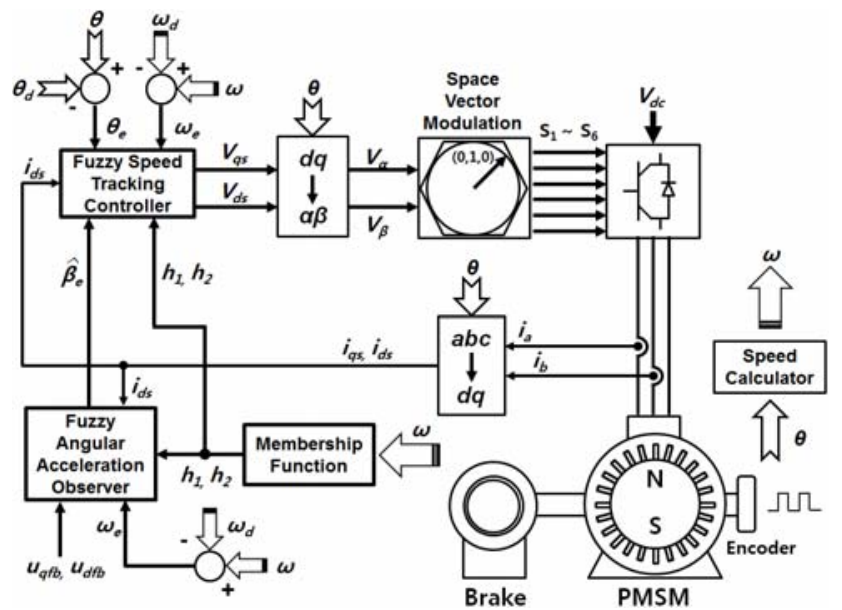

Fig. 4. Overall block diagram of the proposed control system.
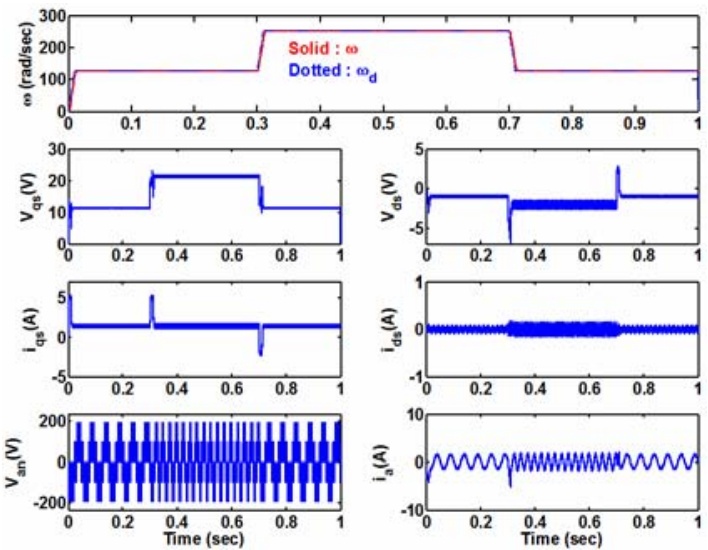

Fig. 5. Simulation results of the proposed method with nominal parameters.

$K_{2}=\left[\begin{array}{cccc}-100.0 & -999750.0 & -2000.0 & 0.0000 \\ 0.0000 & 0.0000 & 0.0000 & -10.0\end{array}\right]$

Based on the controller and observer gains given above, simulations and experiments are executed to verify the proposed control algorithm. Fig. 4 shows an overall block diagram of the proposed control system. As can be seen in Fig. 4, it is composed of a PMSM, an encoder, a brake, a 

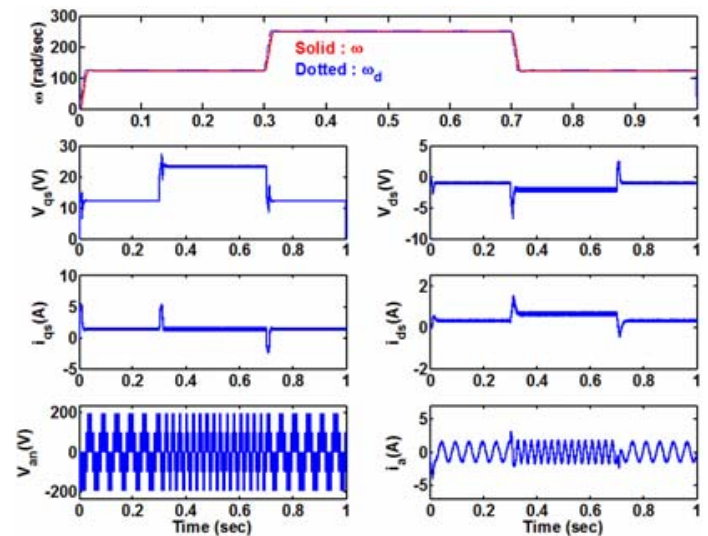

Fig. 6. Simulation results of the proposed method with $150 \%$ variations of some parameters $\left(R_{s}\right.$ and $\left.L_{s}\right)$.
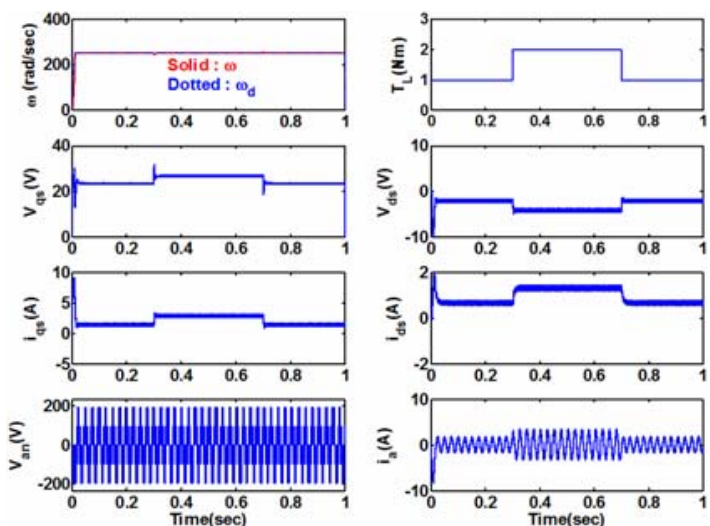

Fig. 7. Simulation results of the proposed method with $150 \%$ variations of some parameters $\left(R_{s}\right.$ and $\left.L_{s}\right)$ when the load torque suddenly changes.
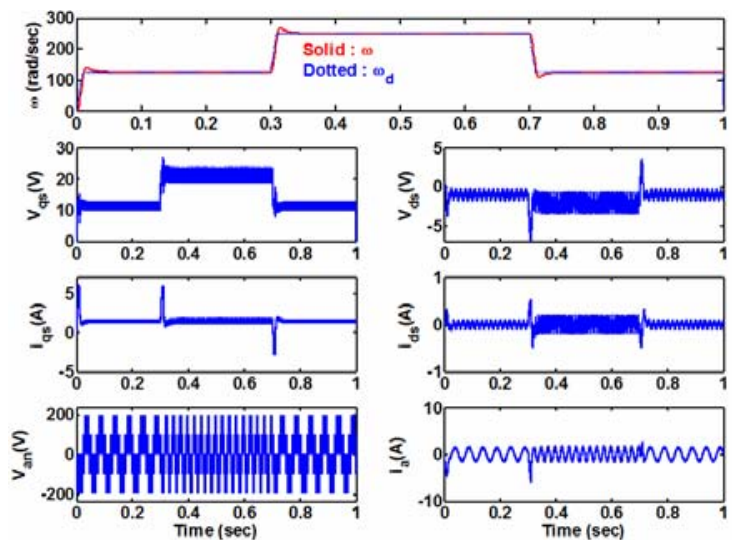

Fig. 8. Simulation results of the conventional PI method with nominal parameters.

three-phase PWM inverter, and a TMS320F28335 DSP. In this paper, the space vector PWM (SVPWM) technique is employed due to its well-known benefits, and the PWM frequency is chosen as $5[\mathrm{kHz}]$.

The proposed control method has been simulated using
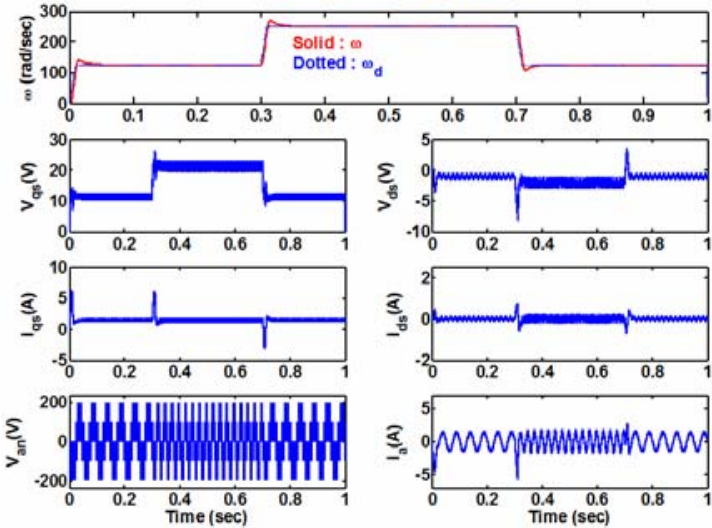

Fig. 9. Simulation results of the conventional PI method with $150 \%$ variations of some parameters $\left(R_{s}\right.$ and $\left.L_{s}\right)$.
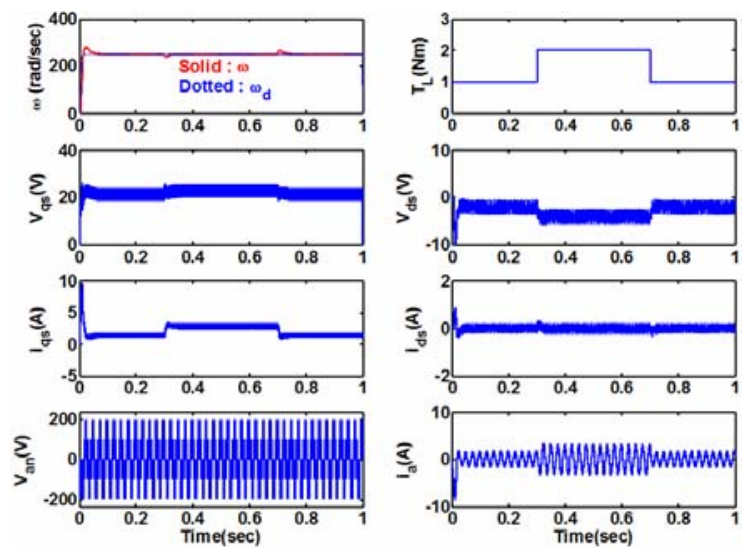

Fig. 10. Simulation results of the conventional PI method with $150 \%$ variations of some parameters $\left(R_{s}\right.$ and $\left.L_{s}\right)$ when the load torque suddenly changes.

Matlab/Simulink. Figs. 5 and 6 show the simulation results $\left(\omega_{d}, \omega, V_{q s}, V_{d s}, i_{q s}, i_{d s}, V_{a n}, i_{a}\right)$ for the speed transient responses under the nominal parameters and $150 \%$ variations of some parameters $\left(R_{s}\right.$ and $\left.L_{s}\right)$. Fig. 7 shows the simulation results for the torque response under $150 \%$ variations of some parameters $\left(R_{s}\right.$ and $\left.L_{s}\right)$. It should be noted that Figs. 6 and 7 are given to show the robustness of the proposed control scheme. Fig. 6 shows the speed transient behavior with $150 \%$ variations of some parameters $\left(R_{s}\right.$ and $\left.L_{s}\right)$ when the desired speed $\left(\omega_{d}\right)$ suddenly changes and the load torque $\left(T_{L}\right)$ is constant, i.e., $\omega_{d}=125.67[\mathrm{rad} / \mathrm{sec}] \rightarrow 251.33[\mathrm{rad} / \mathrm{sec}] \rightarrow$ $125.67[\mathrm{rad} / \mathrm{sec}]$ and $T_{L}=1[\mathrm{~N} \cdot \mathrm{m}]$. Fig. 7 shows the torque transient response with $150 \%$ variations of some parameters $\left(R_{s}\right.$ and $\left.L_{s}\right)$ when the desired speed $\left(\omega_{d}\right)$ is constant and the load torque $\left(T_{L}\right)$ changes with a step, i.e., $\omega_{d}=251.33$ $[\mathrm{rad} / \mathrm{sec}]$ and $T_{L}=1[N \cdot \mathrm{m}] \rightarrow 2[N \cdot \mathrm{m}] \rightarrow 1[N \cdot \mathrm{m}]$. In Figs. 6 and 7 , the proposed observer-based fuzzy controller shows very good control performance under model parameter and load torque variations. 


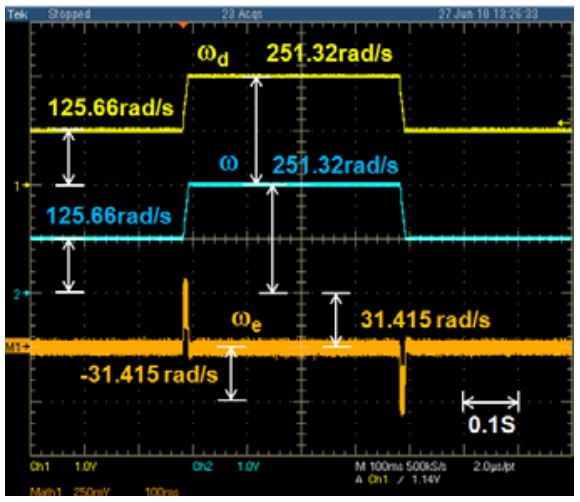

(a) Desired speed $\left(\omega_{d}\right)$, measured speed $(\omega)$ and speed error $\left(\omega_{e}\right)$

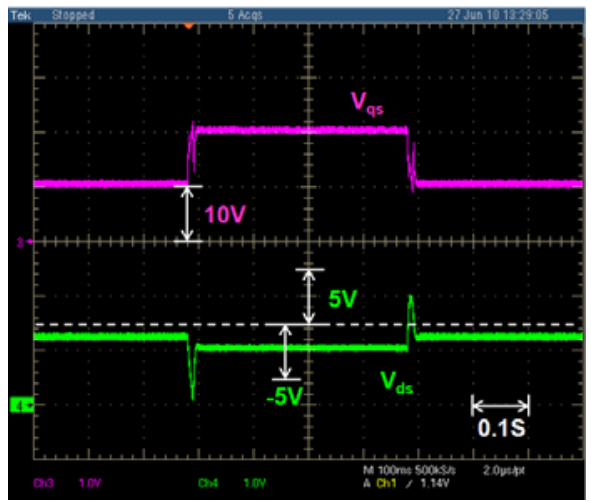

(b) Control voltage inputs $\left(V_{q s}, V_{d s}\right)$

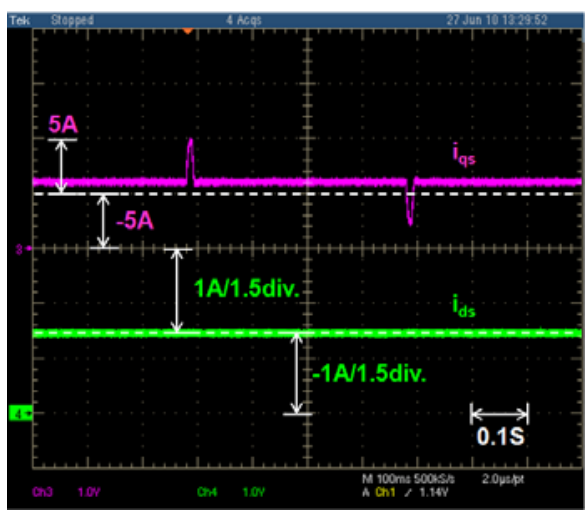

(c) $q$-axis current $\left(i_{q s}\right)$ and $d$-axis current $\left(i_{d s}\right)$

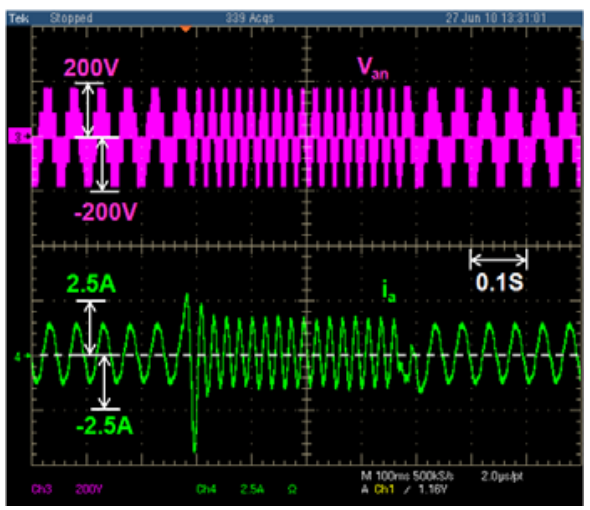

(d) Phase $a$ voltage $\left(V_{a n}\right)$ and phase $a$ current $\left(i_{a}\right)$

Fig. 11. Experimental results with the proposed method under nominal parameters.

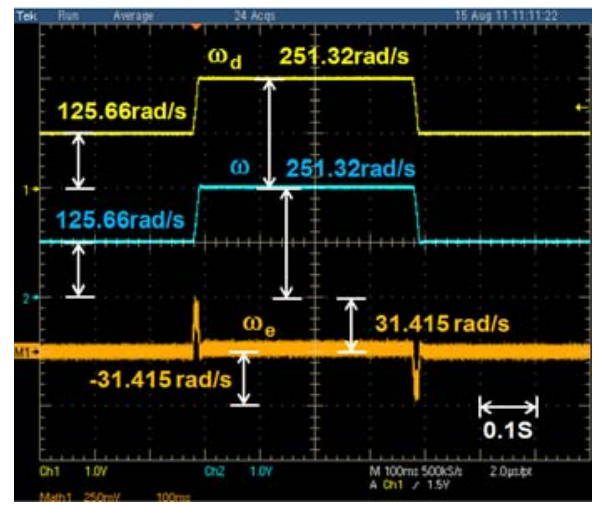

(a) Desired speed $\left(\omega_{d}\right)$, measured speed $(\omega)$ and speed error $\left(\omega_{e}\right)$

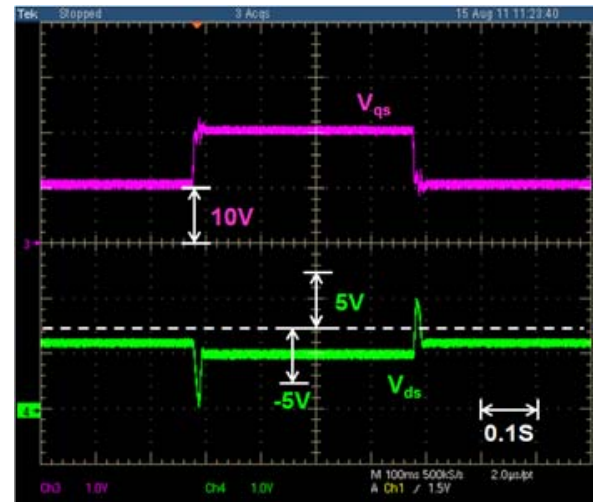

(b) Control voltage inputs $\left(V_{q s}, V_{d s}\right)$

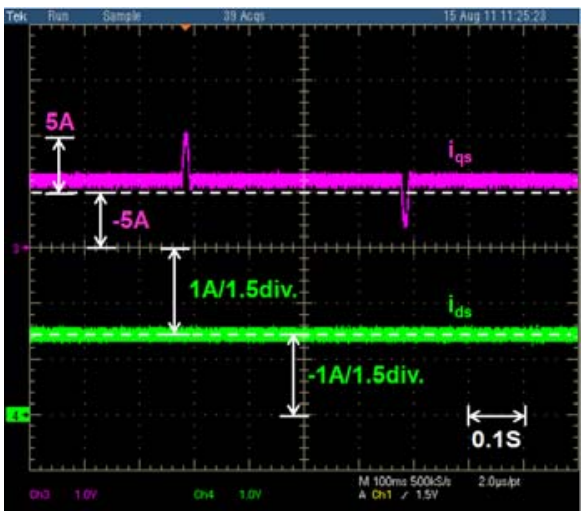

(c) $q$-axis current $\left(i_{q s}\right)$ and $d$-axis current $\left(i_{d s}\right)$

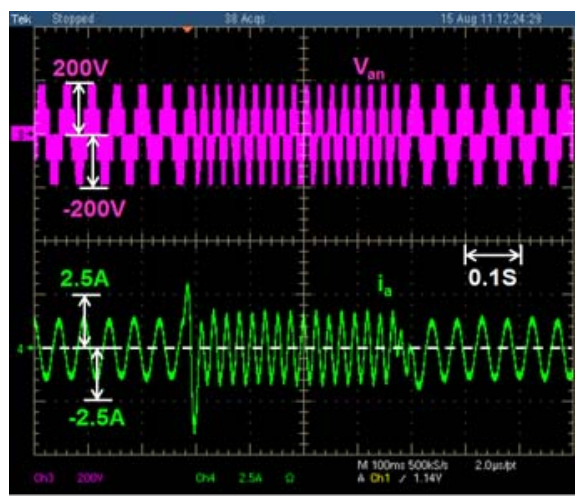

(d) Phase $a$ voltage $\left(V_{a n}\right)$ and phase $a$ current $\left(i_{a}\right)$

Fig. 12. Experimental results with the proposed method under $150 \%$ variations of some parameters $\left(R_{s}\right.$ and $\left.L_{s}\right)$. 


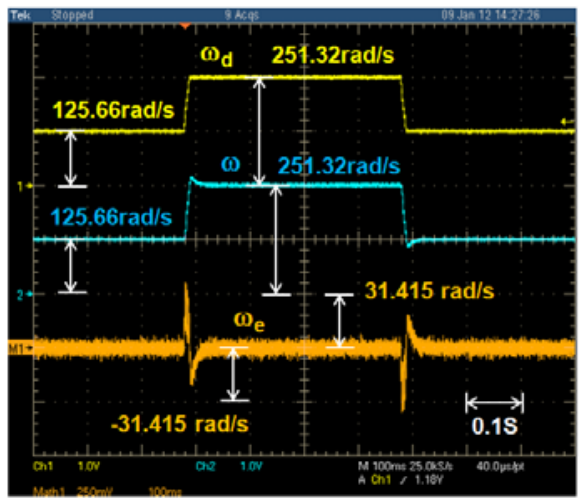

(a) Desired speed $\left(\omega_{d}\right)$, measured speed $(\omega)$ and speed error $\left(\omega_{e}\right)$

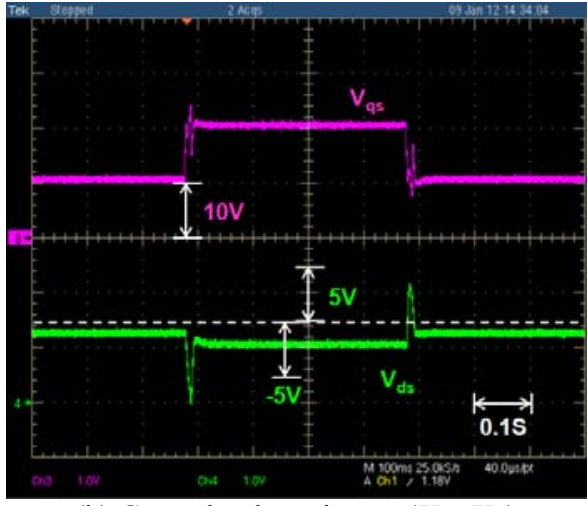

(b) Control voltage inputs $\left(V_{q s}, V_{d s}\right)$

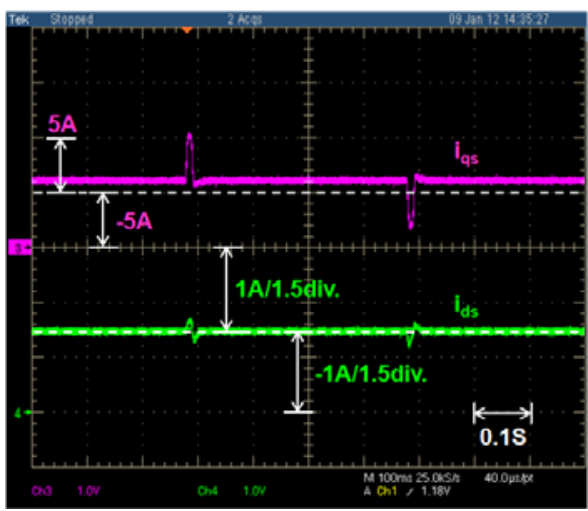

(c) $q$-axis current $\left(i_{q s}\right)$ and $d$-axis current $\left(i_{d s}\right)$

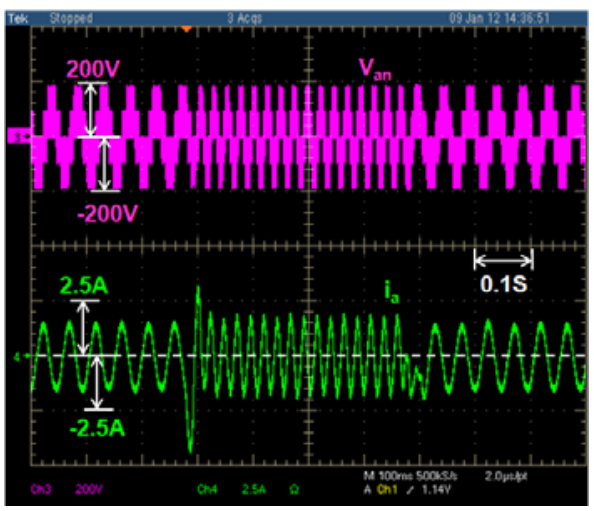

(d) Phase $a$ voltage $\left(V_{a n}\right)$ and phase $a$ current $\left(i_{a}\right)$

Fig. 13. Experimental results with the conventional PI method under nominal parameters.

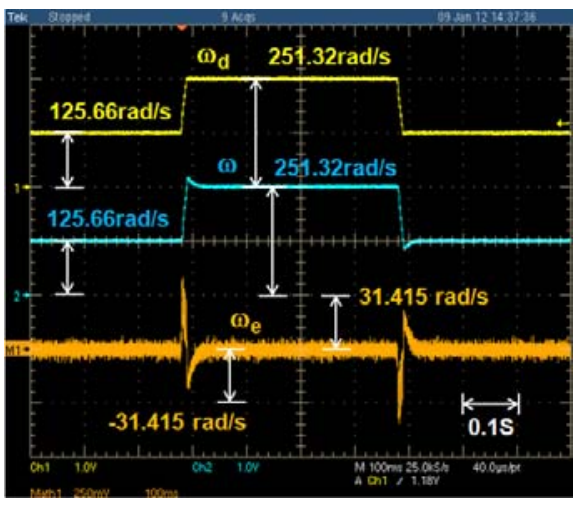

(a) Desired speed $\left(\omega_{d}\right)$, measured speed $(\omega)$ and speed error $\left(\omega_{e}\right)$

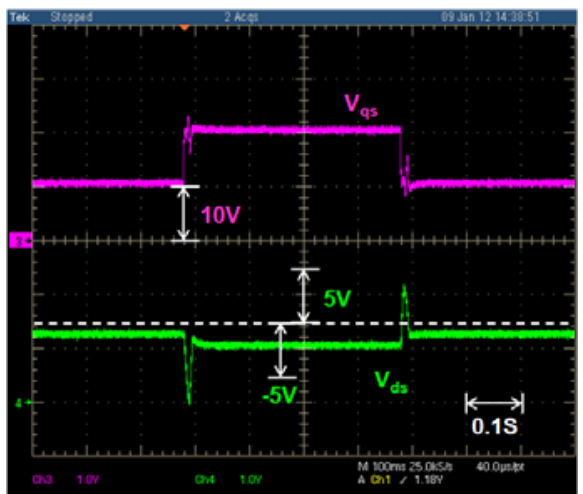

(b) Control voltage inputs $\left(V_{q s}, V_{d s}\right)$

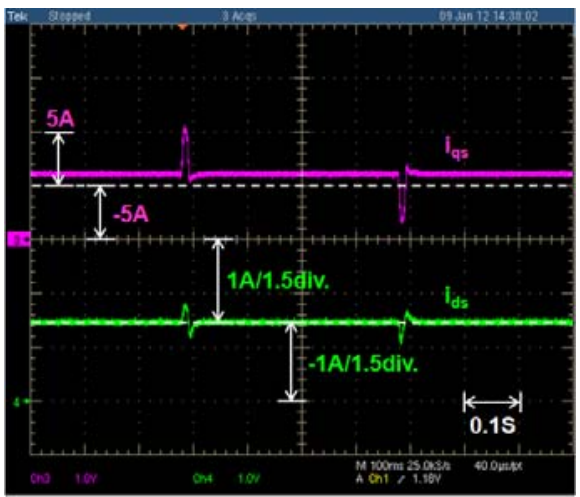

(c) $q$-axis current $\left(i_{q s}\right)$ and $d$-axis current $\left(i_{d s}\right)$

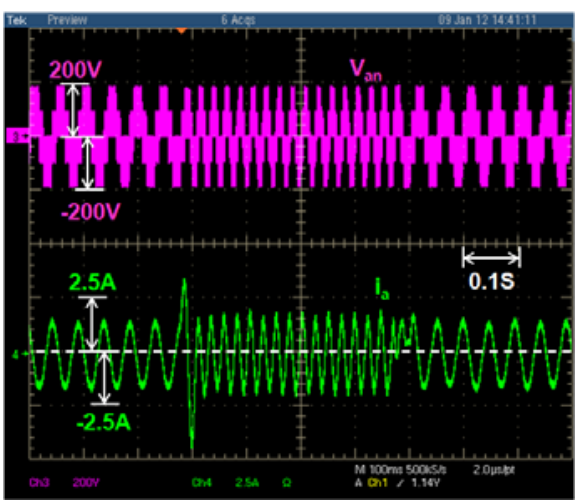

(d) Phase $a$ voltage $\left(V_{a n}\right)$ and phase $a$ current $\left(i_{a}\right)$

Fig. 14. Experimental results with the conventional PI method under $150 \%$ variations of some parameters $\left(R_{s}\right.$ and $\left.L_{s}\right)$. 
For a comparison of the proposed control methodology, the conventional PI control method has also been implemented using Matlab/Simulink under the same conditions as the proposed control method. The conventional PI-PI controller used in this paper contains two PI loops; the PI speed controller in an outer loop and the PI current controller in an inner loop. Also, the PI gains of the speed controller and the current controller are determined based on the general tuning rule [19]-[21]. Figs. 8 to 10 show the simulation results of the conventional PI-PI controller under the same conditions as in Figs. 5 through 7. Figs. 8 and 9 show the transient response when the desired speed $\left(\omega_{d}\right)$ varies. In these figures, the speed response has a larger overshoot $(6.57 \%$ and $7.32 \%$, respectively) and a longer settling time $(0.06 \mathrm{~s}$ and $0.07 \mathrm{~s}$, respectively). Fig. 10 shows the transient response when the load torque $\left(T_{L}\right)$ suddenly changes. In this figure, the motor speed $(\omega)$ is shown to be more unstable during transients than the proposed control method.

In real PMSM drives, the motor parameters always change according to operation conditions even though they are given to be constant in simulation studies. Moreover, it is very difficult to directly change the motor parameters in experiment even if they can easily be changed in simulations. As an alternative to motor parameter variations in a real PMSM, the parameters can be simply changed in the proposed control scheme. Therefore, in this paper, the system parameters are changed in the controller instead of changing the real system parameters of the motor in order to experimentally verify the performance of the controller under $150 \%$ variations of some motor parameters $\left(R_{s}\right.$ and $\left.L_{s}\right)$. Figs. 11 to 12 show the experimental results of the proposed control method under the same conditions as in Figs. 5 and 6, respectively. Meanwhile, Figs. 13 to 14 show the experimental results of the conventional PI control method under the same conditions as in Figs. 8 and 9, respectively. Figs. 11 (a) to 14 (a) show the desired speed $\left(\omega_{d}\right)$, the measured speed $(\omega)$ and the speed error $\left(\omega_{e}\right)$. Figs. 11 (b) to 14 (b) show the control voltage inputs $\left(V_{q s}, V_{d s}\right)$. Figs. 11 (c) to 14 (c) show the measured $q$-axis current $\left(i_{q s}\right)$ and the $d$-axis current $\left(i_{d s}\right)$. Figs. 11 (d) to 14 (d) show the phase $a$ voltage $\left(V_{a n}\right)$ and the phase $a$ current $\left(i_{a}\right)$.

Simulation and experimental results demonstrate that the proposed fuzzy control algorithm can accomplish good speed control performance such as no overshoot, zero steady-state errors, and a fast transient response in comparison with the conventional PI control scheme. Therefore, it can precisely and quickly track the reference trajectory of a SPMSM under motor parameter and load torque variations.

\section{CONCLUSIONS}

A fuzzy tracking controller as well as a fuzzy rotor acceleration observer are proposed in order to accurately follow the desired speed of a PMSM. The proposed observer-based fuzzy tracking control system is insensitive to load torque variations since it does not require the load torque value. The LMI sufficient conditions were derived to obtain the gains for both the fuzzy controller and the fuzzy observer. The stability of the observer-based fuzzy tracking controller was analytically proven. Simulation and experiment results validate that the proposed control scheme can precisely track the desired trajectory of a PMSM in spite of model parameter and load torque variations. The final remarks should be made. A similar method was proposed in [22] but it cannot be directly applied to a trajectory tracking problem. Also, the feasibility of the design problem was not shown in [22].

\section{ACKNOWLEDGMENT}

This research was supported by the Basic Science Research Program through the National Research Foundation of Korea (NRF) funded by the Ministry of Education, Science and Technology (No. 2010-0009577).

\section{REFERENCES}

[1] H. S. Kang, C. K. Kim, and Y. S. Kim, "Position control for interior permanent magnet synchronous motors using an adaptive integral binary observer," Journal of Electrical Engineering \& Technology, Vol. 4, No. 2, pp. 240-248, Jun. 2009.

[2] Y. D. Son and G. H. Kang, "Drive system design for a permanent magnet motor with independent excitation winding for an electric bicycle," Journal of Electrical Engineering \& Technology, Vol. 5, No. 4, pp. 623-630, Nov. 2010.

[3] K. Hartani, Y. Miloud, and A. Miloudi, "Improved direct torque control of permanent magnet synchronous electrical vehicle motor with proportional-integral resistance estimator," Journal of Electrical Engineering \& Technology, Vol. 5, No. 3, pp. 451-461, Sep. 2010.

[4] S. Li and Z. Liu, "Adaptive speed control for permanent-magnet synchronous motor with variations of load inertia," IEEE Trans. Ind. Electron., Vol. 56, No. 8, pp. 3050-3059, Aug. 2009.

[5] T. H. Liu, H. T. Pu, and C. K. Lin, "Implementation of an adaptive position control system of a permanent-magnet synchronous motor and its application," IET Electr. Power Appl., Vol. 4, No. 2, pp. 121-130, 2010.

[6] K. H. Kim, "Model reference adaptive control-based adaptive current control scheme of a PM synchronous motor with an improved servo performance," IET Electr. Power Appl., Vol. 3, No. 1, pp. 8-18, 2009.

[7] C. K. Lin, T. H. Liu, and S. H. Yang, "Nonlinear position controller design with input-output linearisation technique for an interior permanent magnet synchronous motor control system," IET Power Electron., Vol. 1, No. 1, pp. 14-26, 2008.

[8] J. Solsona, M. I. Valla, and C. Muravchik, “ Nonlinear control of a permanent magnet synchronous motor with disturbance torque estimation," IEEE Trans. Energy Convers., Vol. 15 , No. 2, pp. 163-168, Jun. 2000.

[9] S. H. Chang, P. Y. Chen, Y. H. Ting, and S. W. Hung, "Robust current control-based sliding mode control with 
simple uncertainties estimation in permanent magnet synchronous motor drive systems," IET Electr. Power Appl., Vol. 4, No. 6, pp. 441-450, 2010.

[10] S. Chi, Z. Zhang, and Longya Xu, "Sliding-mode sensorless control of direct-drive PM synchronous motors for Washing Machine Applications," IEEE Trans. Ind. Appl., Vol. 45, No. 2, pp. 582-590, Mar./Apr. 2009.

[11] A. R. Ghafari-Kashani, J. Faiz, and M. J. Yazdanpanah, "Integration of non-linear $\mathrm{H}_{\infty}$ and sliding mode control techniques for motion control of a permanent magnet synchronous motor," IET Electr. Power Appl., Vol. 4, No. 4, pp. 267-280, 2010.

[12] Y. S. Kung, C. C. Huang, and M. H. Tsai, "FPGA realization of an adaptive fuzzy controller for PMLSM drive," IEEE Trans. Ind. Electron., Vol. 53, No. 8, pp. 2923-2932, Aug. 2009.

[13] M. N. Uddin and M. A. Rahman, "High-speed control of IPMSM drives using improved fuzzy logic algorithms," 1990, IEEE Trans. Ind. Electron., Vol. 54, No. 1, pp. 190-199, Feb. 2007.

[14] M. Cheng, Q. Sun, and E. Zhou, "New self-tuning fuzzy PI control of a novel doubly salient permanent-magnet motor drive," IEEE Trans. Ind. Electron., Vol. 53, No. 3, pp. 814-821, Jun. 2006.

[15] T. Tagaki and M. Sugeno, "Fuzzy identification of systems and its applications to modeling and control," IEEE Trans. Syst., Man, and Cybern., Vol. 15, No. 1, pp. 116-132, Feb. 1985.

[16] H. H. Choi, "LMI-based nonlinear fuzzy observer-controller design for uncertain MIMO nonlinear systems," IEEE Trans. Fuzzy Syst., Vol. 15, No. 5, pp. 956-971, Oct. 2007.

[17] G. Feng, "A survey on analysis and design of model-based fuzzy control systems," IEEE Trans. Fuzzy Syst. Vol. 14, No. 5, pp. 676-697, Oct. 2006.

[18] S. Boyd, L. El Ghaoui, E. Feron, and V. Balakrishnan, Linear Matrix Inequalities in System and Control Theory, SIAM, PA, 1994.

[19] P. Kshirsagar, R. P. Burgos, A. Lidozzi, J. Jang, F. Wang, D. Boroyevich, and S.-K. Sul, "Implementation and sensorless vector-control design and tuning strategy for SMPM machines in fan-type applications," IEEE Ind. Appl. Conf. IAS Annu. Meeting, Vol. 4, pp. 2062-2069, 2006.

[20] R. H. Middleton and G. C. Goodwin, Digital Control and Estimation: A Unified Approach, Prentice - Hall, Englewood Cliffs, NJ, 1990.

[21] H. Z. Jin and J. M. Lee, "An RMRAC Current Regulator for Permanent-Magnet Synchronous Motor Based on Statistical Model Interpretation," IEEE Trans. Ind. Electron., Vol. 56, No. 1, pp. 169-176, Jan. 2009.

[22] H. H. Choi and J. W. Jung, "Fuzzy speed control with an acceleration observer for a permanent magnet synchronous motor," Nonlinear Dynamics, Vol. 67, No. 3, pp. 1717-1727, Feb. 2012

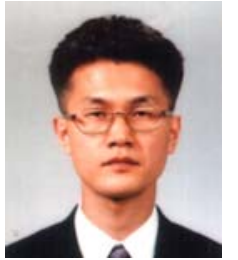

Jin-Woo Jung received his B.S. and M.S. in Electrical Engineering from Hanyang University, Seoul, Korea, in 1991 and 1997, respectively, and his Ph.D. in Electrical and Computer Engineering from The Ohio State University, Columbus, Ohio, USA, in 2005. From 1997 to 2000, he was with the Digital Appliance Research Laboratory, LG Electronics Co., Ltd., Seoul, Korea. From 2005 to 2008, he worked at the R\&D Center and with the PDP Development Team, Samsung SDI Co., Ltd., Korea, as a Senior Engineer. Since 2008, he has been an Associate Professor with the Division of Electronics and Electrical Engineering, Dongguk University, Seoul, Korea. His current research interests include electric machine drives, the control of distributed generation systems using renewable energy sources (wind turbines, fuel cells, solar cells, etc.), the design and control of power converters, and the driving circuits and driving methods of ac plasma display panels (PDP).

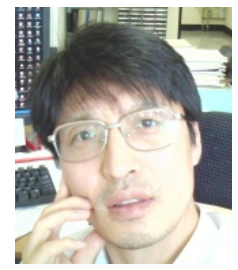

Han Ho Choi received his B.S. in Control and Instrumentation Engineering from Seoul National University (SNU), Seoul, Korea, in 1988, and his M.S. and Ph.D. in Electrical Engineering from KAIST, Daejeon, Korea, in 1990 and 1994, respectively. He is currently with the Division of Electronics and Electrical Engineering, Dongguk University, Seoul, Korea. His research interests include control theory and its application to real world problems.

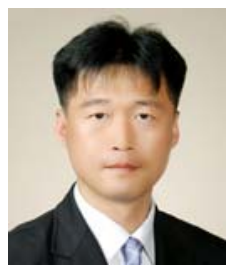

Tae-Heoung Kim received his B.S., M.S., and $\mathrm{Ph} . \mathrm{D}$. in Electrical Engineering from Hanyang University, Seoul, Korea, in 1993, 1995, and 2005, respectively. From 1995 to 2002, he worked for LG Electronics as a Senior Research Engineer. Since 2005, he has been a Professor in the Department of Electrical Engineering, Gyeongsang National University, Jinju, Korea. His research interests include the design of electric machines and control systems. 